\title{
(Dis)entangling medicine and media: a qualitative analysis of the relationship between the fields of healthcare and journalism
}

\section{Sarah Van den Bogaert, Joyce Stroobant \& Piet Bracke}

To cite this article: Sarah Van den Bogaert, Joyce Stroobant \& Piet Bracke (2018): (Dis)entangling medicine and media: a qualitative analysis of the relationship between the fields of healthcare and journalism, Health Sociology Review

To link to this article: https://doi.org/10.1080/14461242.2018.1537131

曲 Published online: 22 Oct 2018.

Submit your article to this journal $\pi$

View Crossmark data \ 


\title{
(Dis)entangling medicine and media: a qualitative analysis of the relationship between the fields of healthcare and journalism
}

\author{
Sarah Van den Bogaert (iD ${ }^{a}$, Joyce Stroobant (1D) ${ }^{b}$ and Piet Bracke ${ }^{a}$ \\ ${ }^{\mathrm{a} D e p a r t m e n t}$ of Sociology, Ghent University, Ghent, Belgium; ${ }^{\mathrm{b}}$ Department of Communication Studies, Ghent \\ University, Ghent, Belgium
}

\begin{abstract}
Previous research has illustrated that journalists play an active role in the production of health news. The current study explores the relationship between the fields of healthcare and journalism from a healthcare perspective. Drawing on Bourdieu's theory of fields and Gieryn's concept of boundary-work, this study employed elite interviewing to analyse how the relations between these two fields were reflected and negotiated in the discourses of Belgian health-policy stakeholders.

Our analysis illustrated that health-policy stakeholders perceived medicine and the news media as two different cultures and, therefore, discursively positioned news media actors as outsiders. Additionally, we showed that the nature of the relationship between health-policy stakeholders and the news media was linked to health-policy stakeholders' position within the healthcare field. Through this analysis, we illustrate the value of using the concept of boundary-work as an analytical instrument to study the relationships between fields.
\end{abstract}

\section{ARTICLE HISTORY}

Received 6 July 2018

Accepted 15 October 2018

\section{KEYWORDS}

Discourse; news media; field; boundary-work; stakeholders; healthcare

\section{Introduction}

Over the past decades, the variety of stakeholders involved in the healthcare field has significantly increased (Conrad, 2005; Pereira Gray, White, \& Russell, 2016). Besides an increase in the number of stakeholders involved in the healthcare field, there is also a more general rise in societal and journalistic interest in health (Clarke, Shim, Mamo, Fosket, \& Fishman, 2003; Weitkamp, 2003). This interest has intensified the interactions between health and media professionals. This relationship between medicine and journalism is often conceptualised as a translation process. That is, media transmit biomedical knowledge in lay terms, hence translating it to a broader audience (Seale, 2002). Several studies, including this one, refute this idea of linear transmission by illustrating that journalists play an active role in the processes of co-production from which health news emerges (e.g. Briggs \& Hallin, 2016; Declercq, 2018). However, while these studies have examined this relationship from a journalistic vantage point, few studies have explored 
a perspective from within the domain of healthcare. Drawing on Bourdieu's theory of fields (Bourdieu, 1983, 2000) and the concept of boundary-work (Gieryn, 1983), our goal is to gain more insight into the complex and often contested relationship between the fields of healthcare and journalism. More specifically, we analysed how these relations are reflected and negotiated in the discourses of health-policy stakeholders, such as government institutions, pharmaceutical companies, and sickness fund agencies. ${ }^{1}$ Drawing on elite interviews with health-policy stakeholders who operate within the Belgian health insurance system, this study addressed the following research questions:

- What is the relationship between health-policy stakeholders and the news media?

- What position do health-policy stakeholders occupy within the healthcare field?

- How do health-policy stakeholders discursively position the news media with reference to the healthcare field? And what motivates them to do so?

Firstly, by studying the interactions of health professionals and journalists, this study advances scholarly understanding of health news production. This is important because health news can have a significant impact on audiences; it is more trusted than information on the Internet (Van Slooten, Friedman, \& Tanner, 2013) and it influences behaviour. Matthews et al. (2016), for instance, show that media coverage of the side effects of statins resulted in decreased therapy adherence. Secondly, we also hope to advance insights regarding the relations between fields, an area which is still less developed than other parts of Bourdieu's field theory (Albright, Hartman, \& Widin, 2018). Lastly, this study aims to understand some of the struggles that are going on within the healthcare field as a result of heightened societal and journalistic interest in health issues.

\section{Bourdieu's theory of fields}

In order to analyse the relationship between health-policy stakeholders and the news media, it is useful to conceptualise the healthcare domain as a field (Bourdieu, 1983; Lewis et al., 2017). A field is 'a relatively autonomous domain of activity that responds to rules of functioning and institutions that are specific to it and which define the relations among the agents' (Hilgers \& Mangez, 2015, p. 6). Collyer, Willis, Franklin, Harley, and Short (2015) explain that a field is not only a social space but also a network of relations between social actors, i.e. 'a site of struggle and contestation' (p. 690). Each field operates according to its own logic and rules and is structured around a set of actors who have certain economic (e.g. material assets) and/or cultural (e.g. knowledge) resources at their disposal. Based on these resources, each actor adopts a certain position within this field. Bourdieu (1983) defines this process as position-taking.

In accordance with Bourdieu's field theory, Collyer (2018) argues that the healthcare sector can be conceptualised as a field. First, being centred around a particular goal (i.e. curing people and/or improving their health) distinguishes the healthcare field from other fields (Collyer, 2018; Thomson, 2008). In order to achieve that goal, the healthcare field operates according to a dominant set of rules and truths (i.e. the (bio)medical model of illness). Although the healthcare field involves various realms (e.g. clinical medicine, science) and thus multiple objectives and truths, all actors are expected to pursue this central goal. However, this does not necessarily mean that actors are actually pursuing 
this goal nor that this is their main goal (e.g. Van den Bogaert, Declercq, Christiaens, Jacobs, \& Bracke, 2018). Second, the healthcare field generates a specific form of capital (i.e. medical knowledge) that is used by actors within the field to gain legitimacy and to determine 'whose main holders are the elites of the field' (Hilgers \& Mangez, 2015, p. 6). Third, the healthcare field is characterised by key actors (e.g. physicians) and a structured set of, often historically formed, positions, e.g. physicians versus nurses or the roles of healthcare providers within specific health insurance systems (Collyer, Willis, \& Lewis, 2017). Finally, the healthcare field operates as a site of struggle between the various actors involved (Collyer et al., 2017). For example, Lewis et al. (2017) state that the healthcare field is an arena in which actors struggle for control over its conditions and what is valued, influencing, for instance, the availability of healthcare services and the very meaning of health itself (p. 3). Nevertheless, while different ideas of health and illness circulate within the healthcare field, the biomedical model still largely dominates.

\section{Field relationality and boundary-work}

A wide range of (new) stakeholders, such as patient organisations, pharmaceutical companies, and news media, are increasingly involved in the healthcare field (Clarke et al., 2003; Pereira Gray et al., 2016). Indeed, the healthcare field is structured around these struggles. On the one hand, the field consists of actors that represent economic and political capital. These actors can be seen as representing external forces that can change the dynamics of the field. This is the heteronomous pole of the healthcare field. On the other hand, the field consists of actors that represent the capital of the field (i.e. medical knowledge) and who want to maintain or improve their position within the field (Benson, 1998; Bourdieu, 2000; Collyer et al., 2015). These actors represent internal forces within the field, and represent the autonomous pole of the healthcare field. As a consequence, fields are dynamic because actors are constantly protecting their position within the field which results in a continuous process of position-taking. In these struggles, the doxa (Bourdieu, 2000) or dominant set of rules and truths of the field is at stake, and thus defines the rules of the game (Collyer, 2018; Thomson, 2008). In this case, the doxa consists of evidencebased medicine and the (bio)medical model of illness (Wagner, Polak, \& ŚwiątkiewiczMośny, 2018). In other words, what is at stake is the definition of health and illness. Collyer (2018) explains that that this doxa strengthens the position of dominant actors, allowing them to defend biomedicine against 'anecdotalism' or claims that are not rigorously supported by scientific evidence, such as those based on a physician's personal experience or case reports. Additionally, the institutionalisation of this doxa impedes other actors, such as alternative practitioners, from claiming legitimacy.

This process of positioning and drawing of boundaries between fields is often a discursive process (Broom \& Tovey, 2007; Burri, 2008; Kerr, Cunningham-Burley, \& Amos, 1998; Mizrachi, Shuval, \& Gross, 2005) in which actors use several strategies in order to (re)establish their position and challenge the position of other actors (Roberts, Hsiao, Berman, \& Reich, 2004; Suddaby \& Viale, 2011; Zietsma \& Lawrence, 2010). These discursive strategies can be grouped into two types. The first strategy is demarcation (Broom \& Tovey, 2007; Kerr et al., 1998), which consists of field actors drawing a line between what is considered as true/good and false/bad within their field (Mizrachi et al., 2005). For example, within the healthcare field, biomedicine is an evidence-based and therefore 
legitimate form of knowledge production (Wagner et al., 2018). Alternative medicine, on the contrary, is constructed as lacking such legitimate forms of evidence and alternative practitioners, in turn, are cast as not having a scientific mind (Broom \& Tovey, 2007). In other words, the strategy of demarcation consists of constructing boundaries around the types of knowledge, procedures, and resources which (do not) belong to the healthcare field. A second, and related, strategy is 'task division' or 'division of labour' (Broom \& Tovey, 2007; Burri, 2008; Mizrachi et al., 2005). By clearly defining the content, specific tasks, and expertise regarding a certain position, actors within a field try to keep other actors out of this position. Mizrachi et al. (2005) illustrate how healthcare professionals secure the boundaries of biomedicine by restricting alternative practitioners to the treatment of the illness experience, thereby making sure that they, as biomedical professionals, stay in charge of the diagnosis and treatment of diseases. Contrary to the first strategy, which attempts to establish the boundaries for the field as a whole, the second strategy defines the internal boundaries of the positions within a field.

What these strategies have in common is that they strengthen the authority and expertise of the actors using them, while at the same time challenging the expertise and motives of other actors who are then positioned as not belonging to or not able to participate within the field (Eldridge, 2016). Additionally, previous studies have shown that this process of discursive positioning is not random, but instead is related to the position an actor takes on within a field (Bourdieu \& Wacquant, 1992; Mizrachi et al., 2005). For example, Broom and Tovey (2007) have illustrated that physicians working in a hospice or palliative care context are less negative about alternative medicine than physicians working in a hospital.

The above-mentioned strategies illustrate that boundary-work takes place in this context. Gieryn (1983) describes boundary-work as 'an ideological style found in scientists' attempts to create a public image for science by contrasting it favourably to nonscientific intellectual or technical activities' (p. 781). He uses the term boundary-work to analyse scientists' attempts to demarcate science from non-science (Albert, Laberge, $\&$ Hodges, 2009). Nevertheless, the concept can also be used to analyse 'the ways in which professionals [in general] seek to establish their skills and jurisdiction over a particular domain of work' (Slembrouck \& Hall, 2013, p. 62).

\section{Field relationality: the journalistic field as a case-study}

The examples discussed in the previous section illustrate that the boundary-work performed by healthcare professionals focuses on restricting the use of so-called non-scientific forms of health knowledge, such as alternative medicine. Another particular type of nonscientific health knowledge production is routinely exercised within the journalistic field. While this form of knowledge production is certainly not exclusive to actors within the journalistic field, it has gained more attention over the past two decades because the means for cheaply producing, disseminating, and consuming information have grown exponentially (Clarke et al., 2003). It is therefore surprising that so few sociological studies have attempted to tackle the relation between, on the one hand, the healthcare field and, on the other hand, the journalistic field.

Marchetti (2010) explicitly draws on Bourdieu's field theory to analyse the interactions between the fields of medicine and journalism. More specifically, he provides a historic 
account of the mediatisation of medicine in France (Marchetti, 2010). Another example can be found in the work of Briggs and Hallin (2016). They argue that these fields of healthcare and journalism cannot be perceived as separate fields, as they constantly draw on each other's logics and practices. For instance, biomedical actors have established press offices and given media training to their staff. Journalists, due to the complexity of contemporary biomedicine, rely heavily on health professionals to interpret biomedical information (Petersen, 2001).

Although Briggs and Hallin (2016) convincingly illustrate that health and media are closely connected, this does not mean that health-policy stakeholders accept journalists and the knowledge they produce as legitimate actors and forms of knowledge within the healthcare field. These tensions are often ascribed to 'cultural' differences. That is, these actors 'differ in their definition of what is newsworthy, their styles of communication, and their vision of the media's role' (Nelkin, 1996, p. 1600). Here Gieryn's (1983) concept of boundary-work offers opportunities. Eldridge (2016) uses the concepts of field and boundary-work to study how journalists deal with the rise of user-generated content and citizen journalists. In order to maintain legitimacy, professional journalists establish boundaries by clearly defining what it means to be a journalist, thereby positioning citizen journalists outside the realm of professional journalism. With his study, Eldridge (2016) illustrates the value of using the concept of boundary-work to understand this complex process of position-taking. The current study applied both concepts (i.e. field theory and boundary-work) to investigate the relationship between the healthcare and journalistic fields, as we believed this framework would permit us to unravel some of the intricacies of this relationship.

\section{Methods}

\section{Sample}

This study formed part of a larger transdisciplinary research project that investigated the complex networks involved in communication on health issues. The project consisted of different research lines which each focused on a different aspect of the health news production process, such as news content (content analysis). The current study formed part of the first research line and drew on elite interviewing in order to chart the different interconnected stakeholders involved in the healthcare field. For the purpose of this larger project, a health-policy stakeholder was defined as an organisation that holds an interest in the Belgian health insurance system or could have had an active influence on the decision-making and implementation process (Bryson, 2004). Therefore, patient organisations and not individual patients were included as healthpolicy stakeholders in our sample. Patient organisations, as opposed to individual patients, we posited, have the resources and capacity to actively participate within the healthcare system, while the latter can only influence health-policy indirectly (Ramirez, 2001).

Our sample of health-policy stakeholders was constructed along six categories (see Table 1). These categories were based on the categories that were most often used in the literature (Britten, 2008; Busfield, 2010). Additionally, these categories were evaluated by two experts who were familiar with the Belgian system. Our final sampling model 
Table 1. Elite interview sample.

\begin{tabular}{lcc}
\hline Health-policy stakeholder & Number of organisations & Number of interviews \\
\hline Pharmaceutical industry & 3 & 5 \\
Government institution & 4 & 8 \\
Sickness Fund Agency & 2 & 6 \\
Patient organisation & 4 & 4 \\
Organisations of scientific medical experts & 2 & 2 \\
Association of healthcare professionals & 3 & 5 \\
TOTAL & 18 & 30 \\
\hline
\end{tabular}

included 18 organisations or health-policy stakeholders. Subsequently, elite interviews, which are interviews with 'those who occupy senior management and board level positions within organisations' (Harvey, 2011, p. 5), were conducted with key informants within each organisation between March and October 2015. Two key figures per organisation were interviewed in order to distinguish between the official organisational rhetoric and personal views. This is a valued approach because it offers an additional quality check (Berry, 2002; Patton, 1999). First, high-ranking management representatives such as Chief Executive Officers and managers were interviewed. Second, since this study was concerned with understanding the interactions of health-policy stakeholders with the news media, communication officers were also interviewed. Table 1 provides an overview of the interview sample.

\section{Data gathering and analysis}

During the interviews, a semi-structured interview schedule containing questions about the organisations' relationship with media professionals and their communication policy was used. Each respondent signed an agreement which guaranteed their anonymity and allowed us to record the interviews. This agreement was accompanied by a document that explained the research project's scope and privacy procedure. Full recording, verbatim transcription of the interviews, and CAQDAS techniques to support data management were used to ensure the quality of the data (Aberbach \& Rockman, 2002). All the transcriptions were coded and scrutinised for discursive devices that exemplified the position-taking of health-policy stakeholders and the boundary-work they performed. These coded fragments were then further analysed through constant comparison. Since the interviews were in Dutch, the quotes used in this paper were translated into English or paraphrased if idiomatic language use made literal translations impossible.

\section{Findings}

In this section, we discuss the complex dynamics observed between health-policy stakeholders and the news media. First, we analyse how health-policy stakeholders drew on media logics and practices, thus illustrating the entanglement between the two fields. Second, we analyse the discursive strategies that were used to position news media actors as outsiders. We then go on to examine whether and how this discursive positioning was related to health-policy stakeholders' position within the healthcare field. 


\section{Entanglement between the healthcare and journalistic fields}

Our results illustrate a complex interplay between the logics and practices of health-policy stakeholders and journalists. The stakeholders in our sample explained that they were often contacted by the media. Journalists contacted these organisations to double check a story, or to obtain statistics or contact information of media-genic patients - those seen by the media as appealing to the audience - or of an expert on the topic at hand. As journalists may lack the medical knowledge to fully comprehend a new study or medical development, they required the expertise of someone from the field. Furthermore, consulting expert sources fits the journalistic ideal of objectivity which at the same time boosts the credibility of a story. The health-policy stakeholders in our sample knew this and, therefore, had started to anticipate the questions of journalists in order to secure better coverage for their news messages. The following excerpt illustrates that when health-policy stakeholders send out press releases, they often provided contact information of academics or healthcare professionals to whom journalists could turn for further information:

We also guide them towards possible interviewees. This morning, even though it was our press release, it was a physician of the academic hospital of Louvain who was interviewed. We know the press prefers someone in a white coat over someone with a tie [laughs]. [...]. We take care of our press releases. They aren't makeshift press releases. We choose our words carefully and they are more or less ready-made (Government institution 1).

The above quote also illustrated that by sending out ready-made bits of information health-policy stakeholders anticipated the needs of journalists, since these information subsidies' (Gandy, 1982) can greatly facilitate the news-making process. The following excerpt illustrates that health-policy stakeholders employed this media logic for their own purposes:

The better your press release, the more it will be copied by journalists. Journalists increasingly have to deal with time constraints. It is convenient for them if a press release is well written and easy to understand. This allows them to copy-paste the message, which is also convenient for us because then we are sure that everything they say is correct (Government institution 2).

These examples illustrate that journalistic logics have entered the healthcare field. Furthermore, the following example shows that health-policy stakeholders actively incorporated these logics into their own professional routines:

Communication officer 1: We have an overview of the number of news articles that were published about us and the topics that were more popular than other topics.

Communication officer 2: We use several indicators to measure what works and what doesn't work.

Interviewer: And what do you do with these results?

Communication officer 1: We discuss them with our sickness fund agencies and, based on these results, we decide on the subjects of future studies and communication activities.

Communication officer 2: For example, when we notice that some topics are not very popular so ... 
Communication officer 1: And other such as depression or ... yes

Interviewer: And you do not cover these less popular topics anymore?

Communication officer 2: Not really no.

Communication officer 1: If we notice that a certain topic is not covered by the press or that it doesn't appear anywhere, perhaps maybe by a couple organisations. Well, then you have to draw conclusions of course (Sickness Fund Agency 2).

Health-policy stakeholders provided media training for their staff, monitored the uptake of their information subsidies, analysed which topics might interest journalists, and adapted their communication strategy accordingly. In other words, health-policy stakeholders have adapted to the rising interest of journalists in health.

\section{Disentangling the fields of healthcare and journalism}

Notwithstanding the incorporation of journalistic logics and practices into the healthcare field, our analysis reveals that health-policy stakeholders mainly focused on the differences between medicine and the news media, since they discursively positioned the news media as belonging to a different field with its own goals, logics, and practices and still considered the production of health news as a translation exercise.

First, health-policy stakeholders emphasised the importance of what they considered to be 'good' health information, which, according to them, had to be produced by medical experts. The following excerpts illustrate this positioning of journalists as lacking medical knowledge:

Our press releases have to be as clear as possible. We do not just have the experts write them, with all due respect, I mean, but we also have them read by a lay person because it is a lay person who will write the article. It's also often frustrating for our scientists that they have to explain the problem to a journalist who is not familiar with the topic and who will write about another subject, such as soccer, an hour later. But that's the way it is (Government institution 2).

The problem is ... those people. It is always someone else and they aren't specialists. Every newspaper maybe has one journalist specialised in health and the others are just journalists who are unenlightened (Organisation of healthcare professionals 1).

Although health-policy stakeholders did not question the skills of journalists to write news messages, and thus to perform their job as a journalist, they did question their expertise concerning health-related topics, thereby questioning the value of the health information produced by journalists.

Second, the health-policy stakeholders in our sample also clearly defined the tasks of actors within the healthcare field (cf. task division), which focus on curing people and improving their health. Journalists' communication styles and judgements of newsworthiness were constructed as not aligning with those of the healthcare field:

It was one of the goals formulated by the Flemish Government when we started our project. We would be a place where journalists could get reliable information. We already warned them [the Flemish Government] that they [journalists] wouldn't contact us very often because the goal of journalists is to cover news. They want to be the first to tell a story. We are often an obstacle because we question their stories. We ask them is that really 
interesting?'. We often have to tell them that the story is of no use, that it's too soon. So we often have to slow them down and they don't like that. (Organisation of medical experts 2).

The above interview excerpt illustrates a journalistic emphasis on newness and speed. Journalists want to be the first to report on a new study, but those often contain preliminary findings or results that are yet to have an impact on patients. Hence, despite journalists' good intentions, their motives are challenged, thereby positioning them as not belonging to the healthcare field.

All the health-policy stakeholders in our sample drew on these discursive strategies. However, we noticed that the reasons behind this boundary-work depended on healthpolicy stakeholders' position within the healthcare field and the extent to which they belonged to the autonomous or heteronomous pole of the healthcare field.

Those stakeholders representing the capital of the field and, thus, belonging to the autonomous pole, can be divided into two groups. First, there were government institutions and organisations of medical experts. These organisations held a relatively stable position within the Belgian healthcare system, and, therefore, did not really have to defend their position within the healthcare field. The main focus of these organisations was the production of scientific information and the development of evidence-based guidelines. These actors constructed medicine and media as two very different cultures and felt that journalists did not belong to the healthcare field because of their style of communication and their definition of the types of health-related issues deemed newsworthy. The representatives in our sample lamented that reporters often sought out extraordinary or sensational angles for covering health-related news, at the expense of scientific accuracy:

I think what often happens is that certain scientific evolutions are immediately constructed as a breakthrough, while in reality you need another 20 years to know if it's really a breakthrough. So that's what happens ... the sensational aspect is often used in news coverage about healthcare. The black sheep or a terrible nursing home. They [news media] often pay a lot of attention to the wrong ... they focus on a single issue. (Government institution 4).

This feeling may be strengthened by the fact that these stakeholders did not perceive the media as a necessary tool for consolidating their own position within the healthcare field Nevertheless, the following example illustrates the complexity of the relationship between these health-policy stakeholders and the news media. One of the representatives of a government institution in our sample felt so strongly about this that she organised a workshop to teach journalists how to interpret and cover scientific information:

We once organised a workshop for journalists because we noticed that there were a lot of "eureka" news articles about new scientific studies. And they all say "wow look at that" but then you discover that it has only been tested on mice. [...] We organised that workshop to teach them how to analyse those press releases. What should you be looking for? Are there conflicts of interests? How do you interpret that? (Government institution 1).

Interestingly, during the workshop, the government institution not only focused on dealing with scientific information but also on searching for conflicts of interests, which is a journalistic logic rather than a scientific one. Hence, this example illustrates that despite the boundary-work performed by these government institutions, journalistic and scientific logics are strongly intertwined. 
A second group on the autonomous pool are associations of healthcare professionals. Their main resource within the healthcare field is the medical knowledge and expertise they hold. Contrary to government institutions and organisations of medical experts, these associations are much more concerned with the impact of news coverage on the public's perception of their profession. The following excerpt illustrates these concerns:

Representative: the press are looking for something that is newsworthy and that's not always easy. If we communicate about the role of [name of profession] that is not sexy enough for the press. We notice that they mainly contact us when there is a problem. [...]

Interviewer: Are there topics that deserve more media attention?

Representative: A positive message and in-depth coverage of a certain topic. This is something that is hard to get into the news. You have to find something that catches their eye, otherwise they do not cover it. And that's a shame. It all has to be flashy and short and I don't know what else. There isn't enough in-depth coverage of positive news. I think that we still have a lot of things to tell about [name of profession] which the general public doesn't know about the [name of profession], but we don't get the chance (Association of healthcare professionals 1).

Before turning to two health-policy stakeholders that can be considered as representing the heteronomous pole of the healthcare field, we examine one stakeholder that represents both poles; sickness fund agencies (SFA). SFAs are embedded within the healthcare system, because health insurance is organised through them. So, on the one hand, they possess a certain amount of medical knowledge and expertise and a rather stable position within the field. On the other hand, SFAs are also economic and political actors, which makes them actors drawing on the heteronomous pole of the healthcare field. More specifically, they are social entrepreneurs that offer services such as cleaning services to their members, private insurers who offer complementary private health insurance, and they also want to attract new members in order to be able to weigh more on policydecisions. These various functions play a role when SFAs communicate to the news media. When asked about their reasons to communicate to the media, the communication officer of a SFA explained:

Partly because of the image. If you communicate it is always to make sure that you [as organisation] look good (Sickness fund agency 1).

The possible impact of news media on SFAs' reputation played an important role in sickness fund agencies' communication policy. SFAs, therefore, had to find a balance between the content they want to deliver and the marketing aspect of this message:

It's difficult to find a balance between ... yes we [SFAs] compete with each other for members. So, marketing is important for us. It's a shame that I have to say that but it's like that. Sometimes we find our messages [the ones that are picked up by the news media] a little bit too trivial. Other messages, on which we worked really hard, are more difficult to understand, and are, therefore, not picked up by the news media. That's frustrating (Sickness fund agency 2).

The above quote also illustrates the complex interplay between SFAs and journalists. On the one hand, we noticed that the representatives in our sample found it hard to get media attention for certain topics and believed that some topics were neglected by the news 
media. They perceived journalists as holding differing definitions of newsworthiness. On the other hand, in order to gain publicity, they adapted their communication messages to these journalistic values.

Finally, there were two groups of health-policy stakeholders, the pharmaceutical industry and patient organisations, who represented forms of capital (i.e. economic capital and lay knowledge) that belonged to the heteronomous pole of the healthcare field. First, the pharmaceutical industry can be considered as a strong economic force, since they are the second largest employer in Belgium and invest billions in research and development (Pharma.be, 2016). Due to their economic position, they are included in various consultation bodies and are able to influence health-policy decisions. Nevertheless, they constantly have to defend their position, since their motives are often questioned by other actors, such as sickness fund agencies or patient organisations (Test-aankoop, 2016). They also have a rather difficult relationship with the media. One representative explained that they were often confronted with hostile journalists and negative headlines:

We have noticed that it isn't easy as a pharmaceutical company ... in the media ... how do I have to explain that ... to get a fair chance. It is not about good or bad, it is about getting a fair chance (Pharmaceutical industry 3 ).

It is not surprising that the industry's definition of newsworthiness did not align with that of the news media, given the industry wants to avoid stories that might lead to more restrictive legislation or questions about their pricing policy (Van den Bogaert et al., 2018).

A second actor representing the heteronomous pole were patient organisations, which are rather new actors within the healthcare field. Historically, SFAs were seen as the defenders of patients. However, gradually, SFAs have taken on more and different roles, thus creating opportunities for patient organisations to improve their position within the field (Van den Bogaert, Ayala, \& Bracke, 2017). Although increasingly included in various consultation bodies, patient organisations are still excluded from substantial parts of the health policy-making process. In order to position themselves as legitimate actors within the healthcare field, patient organisations actively collaborated with news media. For instance, when talking about the content of their communication messages, the representatives explained that they always included their policy demands because, given their peripheral position within their own field, they hoped to gain more leverage via the mainstream media:

Our messages contain an overview of the problem at hand or the research that was conducted. We report the findings and then we formulate our policy demands. What has to change in order to solve the problem or improve the situation. (Patient organisation 2).

Patient organisations perceived news coverage as an instrument for establishing their expertise in the eyes of the public. As such, journalists were viewed as allies rather than opponents in patient organisations' struggles to contribute to the healthcare field. Consequently, they less explicitly positioned the news media as outsiders. Nevertheless, as the following excerpt illustrates, by explicitly positioning themselves as experts on which the news media can draw to obtain more information, they implicitly drew a boundary and positioned the news media as lacking medical expertise: 
Representative 1: We are often contacted. If they [journalists] read something from abroad about a new study, they ask us if that is interesting, or they ask us to refer them to an expert who can tell them more about that study, or to comment on the study.

Interviewer: And do they call often?

Representative 2: Actually, they do.

Representative 1: Yes yes.

Representative 2: I think that they call us first before they call a professor or a hospital. (Patient organisation 4).

For journalists, patient organisations might be interesting because they represent lay viewpoints and because they can be useful for locating patients who can share their personal experiences. These examples illustrate the complexity of the relationship between patient organisations and journalists and suggest that although patient organisations drew on journalistic logics and practices, their expectations of journalists' roles might differ from how journalists themselves perceive their own role.

\section{Conclusion}

Drawing on elite interviews, this study has analysed the intricate interplay between health-policy stakeholders and news media actors. Contrary to previous research, which investigated this relationship from the media perspective (Briggs \& Hallin, 2016; Declercq, 2018), this study focused on the perspective of health-policy stakeholders and also studied how health-policy stakeholders try to make these fields seem separate.

Drawing on Bourdieu's (1983) field theory and Gieryn's (1983) concept of boundarywork, we illustrated that despite the existence of intricate interdependencies among actors from both fields, health-policy stakeholders discursively positioned news media actors as outsiders, thus, engaging in boundary-work. Consequently, our analysis advances the scholarly understanding of this relationship. Firstly, our study illustrates that health-policy stakeholders' discourses reflect the two cultures trope (Nelkin, 1996). Journalists were positioned as lacking the knowledge to define what constitutes health and illness, as having a different definition of newsworthiness, and as having a different style of communication. This is an interesting finding because it illustrates that health-policy stakeholders use boundary-work to deal with the complex entanglement between medicine and the news media. By referring to the two cultures trope, health-policy stakeholders on the one hand acknowledge news media's involvement in the health news production process, as they do not question journalists' skills to write news messages. On the other hand, by referring to different cultures, news media actors are positioned as outsiders. Secondly and most importantly, we unravelled that the nature of the relation between health-policy stakeholders and news media actors was linked to health-policy stakeholders' position within the healthcare field. We showed that actors who were strongly embedded within the healthcare field, such as government institutions and organisations of medical experts, were not actively trying to engage with the news media to consolidate their position within the healthcare field. However, they did engage with the news media for other purposes, such as 
communicating the results of a new study to lay audiences. Other stakeholders, such as SFAs and patient organisations, actively drew on the news media in order to consolidate their position. This link between an actors' position within the healthcare field and their approach towards the news media is clearly illustrated in the case of SFAs who mainly drew on news media for safeguarding their economic and political position. The pharmaceutical industry and associations of healthcare professionals were more cautious when it came to interacting with journalists, because the news media could destabilise their position within the healthcare field by turning public opinion against them. Therefore, the news media were approached either with suspicion or not at all. Finally, patient organisations perceived news media as a partner in their struggle to improve their position within the healthcare field.

Additionally, we illustrated that the concept of boundary-work could provide a valuable analytical instrument for understanding how relationships among fields are shaped, contested, and consolidated, because it specifically focuses on these relationships. Moreover, our study illustrated that by focusing on field relationality, we were able to shed light on how the field as a whole and its boundaries are constantly (re)constructed. For instance, the discursive strategies used by the health-policy stakeholders in our sample revealed that biomedicine and the biomedical model were seen as central to the healthcare field and that, in order to be considered as legitimate, knowledge production within the field had to follow its rules.

Notwithstanding these contributions, our study is limited to health-policy stakeholders and their perceptions of the journalistic field. Since the assumptions of health-policy stakeholders about the journalistic field do not always align with the reality of the news room, future research may benefit from complementing the current results with an analysis of the boundary-work performed by journalists. Additionally, since the healthcare field is increasingly permeated by various fields, future research could examine the interactions of the healthcare field with other fields. For instance, the involvement of large multinational pharmaceutical companies and the marketisation of health and healthcare, which has brought economic logics and practices to the healthcare field, could provide interesting terrain for analysis (Busfield, 2010; Clarke et al., 2003).

Finally, although our study is limited to the Belgian context, these changes within the healthcare field form part of a more global evolution of the healthcare field, from a space mainly occupied and dominated by the medical profession towards an increasingly diverse and contested space (Busfield, 2010; Clarke et al., 2003). This struggle over knowledge and positions within a field is also not unique to the healthcare field; they form part of a more general trend in which knowledge is increasingly diverse and contested. For instance, a similar struggle is currently underway within the journalistic field, where journalists struggle with the rise of digital journalism and the news produced by these digital interlopers (Eldridge, 2016).

\section{Note}

1. Sickness fund agencies are non-profit private health insurance organisations which collect health insurance contributions. Within social health insurance systems, health insurance is organised through these organisations. 


\section{Acknowledgements}

We are grateful to all the organisations and anonymous representatives who were willing to act as interviewees. For helping us to have access to these organisations, we have Thierry Christiaens and Marc Bogaert to thank. We are also grateful to all the members of the Health, Media \& Society research centre, and special thanks go to Henk Roose for sharing his insights on field theory.

\section{Disclosure statement}

No potential conflict of interest was reported by the authors.

\section{Funding}

This work was supported by the Special Research Fund (BOF) of Ghent University [grant number BOF14-GOA-014].

\section{ORCID}

Sarah Van den Bogaert (D) http://orcid.org/0000-0001-5671-8642

Joyce Stroobant (1D) http://orcid.org/0000-0003-1460-748X

\section{References}

Aberbach, J. D., \& Rockman, B. A. (2002). Conducting and coding elite interviews. Political Science \& Politics, 35(4), 673-676.

Albert, M., Laberge, S., \& Hodges, B. D. (2009). Boundary-work in the health research field: Biomedical and clinician scientists' perceptions of social science research. Minerva, 47(2), 171-194.

Albright, J., Hartman, D., \& Widin, J. (2018). Bourdieu's field theory and the social sciences. Singapore: Springer Nature.

Benson, R. (1998). Field theory in comparative context: A new paradigm for media studies. Theory and Society, 28(3), 463-498.

Berry, J. M. (2002). Validity and reliability issues in elite interviewing. Political Science \& Politics, 35 (4), 679-682.

Bourdieu, P. (1983). The field of cultural production, or: The economic world reversed. In R. Johnson (Ed.), The field of cultural production: Essays on Art and literature (pp. 29-73). Cambridge: Polity Press.

Bourdieu, P. (2000). Pascalian meditations. Stanford: Polity Press.

Bourdieu, P., \& Wacquant, L. J. (1992). An invitation to reflexive sociology. Chicago: University of Chicago press.

Briggs, C. L., \& Hallin, D. C. (2016). Making health public: How news coverage is remaking media, medicine, and contemporary life. New York: Routledge.

Britten, N. (2008). Medicines and society. Basingstoke: Palgrave Macmillan.

Broom, A., \& Tovey, P. (2007). Therapeutic pluralism? Evidence, power and legitimacy in UK cancer services. Sociology of Health \& Illness, 29(4), 551-569.

Bryson, J. M. (2004). What to do when stakeholders matter: Stakeholder identification and analysis techniques. Public Management Review, 6(1), 21-53.

Burri, R. V. (2008). Doing distinctions: Boundary work and symbolic capital in radiology. Social Studies of Science, 38(1), 35-62.

Busfield, J. (2010). 'A pill for every ill': Explaining the expansion in medicine use. Social Science and Medicine, 70(6), 934-941. 
Clarke, A. E., Shim, J. K., Mamo, L., Fosket, J. R., \& Fishman, J. R. (2003). Biomedicalization: Technoscientific transformations of health, illness, and U.S. biomedicine. American Sociological Review, 68(April), 161-194.

Collyer, F. M. (2018). Envisaging the healthcare sector as a field: Moving from Talcott Parsons to Pierre Bourdieu. Social Theory \& Health, 16(2), 111-126.

Collyer, F. M., Willis, K. F., Franklin, M., Harley, K., \& Short, S. D. (2015). Healthcare choice: Bourdieu's capital, habitus and field. Current Sociology, 63(5), 685-699.

Collyer, F. M., Willis, K. F., \& Lewis, S. (2017). Gatekeepers in the healthcare sector: Knowledge and Bourdieu's concept of field. Social Science \& Medicine, 186(August 2017), 96-103.

Conrad, P. (2005). The shifting engines of medicalization. Journal of Health and Social Behavior, 46 (1), 3-14.

Declercq, J. (2018). Balancing journalists' and scientists' professional practices. Journal of Applied Linguistics and Professional Practices, 13(1-3). [In Press].

Eldridge, S. (2016). The digital journalist: The journalistic field, boundaries, and disquieting change. In B. Franklin \& S. Eldridge (Eds.), The Routledge companion to digital journalism studies (pp. 44-54). London: Routledge.

Gandy, O. H. (1982). Beyond agenda setting: Information subsidies and public policy. Norwood: Ablex Publishing Corporation.

Gieryn, T. F. (1983). Boundary-work and the demarcation of science from non-science: Strains and interests in professional ideologies of scientists. American Sociological Review, 48(1983), 781795.

Harvey, W. S. (2011). Strategies for conducting elite interviews. Qualitative Research, 11(4), 431441.

Hilgers, M., \& Mangez, E. (2015). Bourdieu's theory of social fields: Concepts and applications. New York, NY: Routledge.

Kerr, A., Cunningham-Burley, S., \& Amos, A. (1998). The new genetics and health. Public Understanding of Science, 7(1), 41-60.

Lewis, S., Collyer, F., Willis, K., Harley, K., Marcus, K., Calnan, M., \& Gabe, J. (2017). Healthcare in the news media: The privileging of private over public. Journal of Sociology. Advance online publication. doi:10.1177/1440783317733324

Marchetti, D. (2010). Quand la santé deviant médiatique. Grenoble: Presses universitaires de Grenoble.

Matthews, A., Herrett, E., Gasparrini, A., Van Staa, T., Goldacre, B., Smeeth, L., \& Bhaskaran, K. (2016). Impact of statin related media coverage on use of statins: Interrupted time series analysis with UK primary care data. The British Medical Journal, 353, i3283.

Mizrachi, N., Shuval, J. T., \& Gross, S. (2005). Boundary at work: Alternative medicine in biomedical settings. Sociology of Health \& Illness, 27(1), 20-43.

Nelkin, D. (1996). An uneasy relationship: The tensions between medicine and the media. The Lancet, 347(9015), 1600-1603.

Patton, M. Q. (1999). Enhancing the quality and credibility of qualitative analysis. Health Services Research, 34(5 Pt 2), 1189-1208.

Pereira Gray, D., White, E., \& Russell, G. (2016). Medicalisation in the UK: Changing dynamics, but still ongoing. Journal of the Royal Society of Medicine, 109(1), 7-11.

Petersen, A. (2001). Biofantasies: Genetics and medicine in the print news media. Social Science of Medicine, 52(8), 1255-1268.

Pharma.be. (2016). Pharma figures 2016. Brussels: Pharma.be.

Ramirez, R. (2001). Understanding the approaches for accommodating multiple stakeholders' interests. International Journal of Agricultural Resources, Governance and Ecology, 1(3), 264-285.

Roberts, M. J., Hsiao, W., Berman, P., \& Reich, M. R. (2004). Getting health reform right: A guide to improving performance and equity. Oxford: Oxford University Press.

Seale, C. (2002). Media \& health. Thousand Oaks: Sage.

Slembrouck, S., \& Hall, C. (2013). Boundary work. In C. Hall, K. Juhila, M. Matarese, \& C. Van Nijnatten (Eds.), Analysing social work communication: discourse in practice (pp. 61-78). London: Routledge. 
Suddaby, R., \& Viale, T. (2011). Professionals and field-level change: Institutional work and the professional project. Current Sociology, 59(4), 423-442.

Test-Aankoop. (2016). Genees de geneesmiddelenindustrie: teken onze petitie. Retrieved from http://www.testaankoop.be/gezondheid/geneesmiddelen/nieuws/genees-de-geneesmiddelenind ustrie-tekenonze-petitie\#startpetition

Thomson, P. (2008). Field. In M. Grenfell (Ed.), Pierre Bourdieu: Key concepts (pp. 67-81). Stocksfield: Acumen.

Van den Bogaert, S., Ayala, R. A., \& Bracke, P. (2017). Beyond ubiquity: Unravelling medicalisation within the frame of health insurance and health-policy making. Social Theory and Health, 15(4), 407-429.

Van den Bogaert, S., Declercq, J., Christiaens, T., Jacobs, G., \& Bracke, P. (2018). In the land of pharma: A qualitative analysis of the reputational discourse of the pharmaceutical industry. Public Relations Inquiry, 7(2), 127-147.

Van Slooten, E., Friedman, D. B., \& Tanner, A. (2013). Are we getting the health information we need from the mass media? An assessment of consumers' perceptions of health and medical news Journal of Consumer Health on the Internet, 17(1), 35-53.

Wagner, A., Polak, P., \& Świątkiewicz-Mośny, M. (2018). Who defines-who decides? Theorising the epistemic communities, communities of practice and interest groups in the healthcare field. Social Theory \& Health. Advance online publication. doi:10.1057/s41285-018-0073-6s41285018-0073-6

Weitkamp, E. (2003). British newspapers privilege health and medicine topics over other science news. Public Relations Review, 29(3), 321-333.

Zietsma, C., \& Lawrence, T. B. (2010). Institutional work in the transformation of an organizational field: The interplay of boundary work and practice work. Administrative Science Quarterly, 55 (2010), 189-221. 